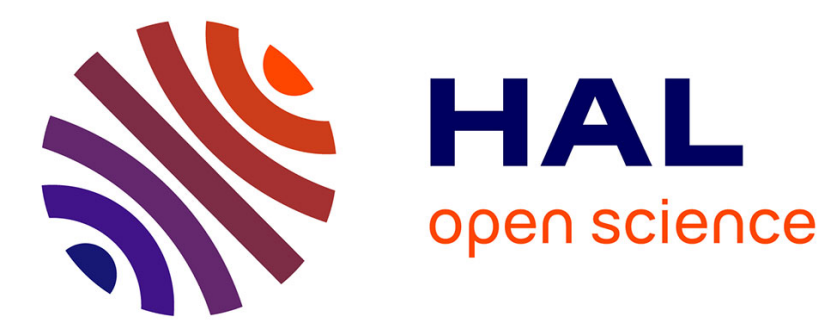

\title{
STUDIES OF U.V. STIMULATED LUMINESCENCE FROM H2O ICE
}

R. Litjens, T. Quickenden

\section{To cite this version:}

R. Litjens, T. Quickenden. STUDIES OF U.V. STIMULATED LUMINESCENCE FROM H2O ICE. Journal de Physique Colloques, 1987, 48 (C1), pp.C1-59-C1-65. 10.1051/jphyscol:1987109 . jpa00226239

\section{HAL Id: jpa-00226239 https://hal.science/jpa-00226239}

Submitted on 1 Jan 1987

HAL is a multi-disciplinary open access archive for the deposit and dissemination of scientific research documents, whether they are published or not. The documents may come from teaching and research institutions in France or abroad, or from public or private research centers.
L'archive ouverte pluridisciplinaire HAL, est destinée au dépôt et à la diffusion de documents scientifiques de niveau recherche, publiés ou non, émanant des établissements d'enseignement et de recherche français ou étrangers, des laboratoires publics ou privés. 


\title{
STUDIES OF U.V. STIMULATED LUMINESCENCE FROM $\mathrm{H}_{2} \mathrm{O}$ ICE
}

\author{
R.A.J. LITJENS and T.I. QUICKENDEN ${ }^{(1)}$ \\ Department of Physical and Inorganic Chemistry, The University \\ of Western Australia, Nedlands W.A. 6009, Australia
}

\begin{abstract}
Résumé - Des mesures de variation thermique sur la bande de luminescence à $340 \mathrm{~nm}$ émise sous excitation UV dans la glace ont été associées avec des données concernant la mobilité des centres émetteurs de manière à les identifier. L'émetteur le plus probable à $340 \mathrm{~nm}$ est associé à la transition $\mathrm{A}^{2} \mathbf{z}_{\rightarrow} \rightarrow \mathrm{X}^{2}$ II du groupement of déplacée vers le bleu par rapport à sa valeur dans la phase gazeuse $(306,4 \mathrm{~nm})$. Ce déplacement est expliqué de manière simple par la perturbation des facteurs de Frank-Condom par le réseau de la glace de sorte que le recouvrement maximum se produit une unité au-dessus de la diagonale principale favorisant ainsi la transition vibrationnelle $v^{\prime}=0 \rightarrow-\rightarrow v^{\prime}=1$ plutôt que celle relative à $v^{\prime}=0 \rightarrow-\rightarrow v^{\prime \prime}$ $=0$.
\end{abstract}

ABSTRACT - Temperature-dependence measurements on the $340 \mathrm{~nm}$ luminescence band emitted by U. V. -excited $\mathrm{H}_{2} \mathrm{O}$ ice were combined with information about species mobilities, to assist in the identification of the emitting species. It was concludgd that the most likely emitter of the $340 \mathrm{~nm}$ band is the $A_{\Sigma}^{2}--->X^{2} \pi$ transition of $O H$, blue shifted from its gas phase value of $306.4 \mathrm{~nm}$. The simplest explanation of this shift is that it ocours because of the perturbation of Franck-condon. factors by the ice matrix so that maximum overlap occurs one unit above the main diagonal, thus favouring the $v^{\prime}=0,-\rightarrow v^{\prime}=1$ vibrational transition rather than the $v^{\prime}=0-->v^{\prime}{ }^{\prime}=0$ transition.

\section{INTRODUCTION}

Previous studies by the present workers [1] have examined the spectral characteristics of the luminescence emitted by lowtemperature crystaline $\mathrm{H}_{2} \mathrm{O}$ ice excited by $200-280 \mathrm{~nm}$ ultraviolet light. The resulting luminescence was comprised of two broad bands with peaks at 340 and $420 \mathrm{~nm}$ respectively, and which were preferentially excited by 220 and $260 \mathrm{~nm}$ light. The luminescence excitation and emission spectra increased in intensity with irradiation time and exhibited a memory effect when the excitation was discontinued and recommenced at a later time. This paper describes a study of the temperature dependence of the $340 \mathrm{~nm}$ emission band and a study of its dependence on irradiance. Such information is of assistance in identifying the species and processes which lead to light emission.

(I) Please address alI correspondence to : T.I. Quickenden, at the above address 


\section{EXPERIHENTAL}

The luminescence was excited in an evacuated irradiation cel I by U. V. light from a doubly-monochromated high-pressure mercury lamp and the luminescence was measured after monochromation using photon-counting equipment. This equipment and the evacuated irradiation cell have been described in detail previously [1]. When necessary, the irradiance of the exciting light was reduced by fixed amounts by inserting into the light path calibrated optical filters made by depositing various thicknesses of gold on to silica substrates. Water used for the preparation of ice samples was carefully purified from potentially-luminescent impurities as described previously [1,2]. Crystaliine ice samples were prepared by a previously-described method [1] and were irradiated in a vacuum of $4 \times 10^{-2}$ Torr. All errors quoted in this work are $50 \%$ confidence intervals.

\section{HESULTS AHD DISCUSSION}

\subsection{The_Effect_of Teq}

The effect of temperature on the 340 nm emission was determined by slowly warming the ice and measuring the luminescence intensity at selected temperatures while it was being irradiated. It was shown by warming the ice in the absence of U.V. irradiation that no detectable thermoluminescence was present. As the luminescence intensity accumulates [1] with continued irradiation, complications due to intensity increases were avoided by irradiating the ice only during the brief periods when luminescence measurements were being made.

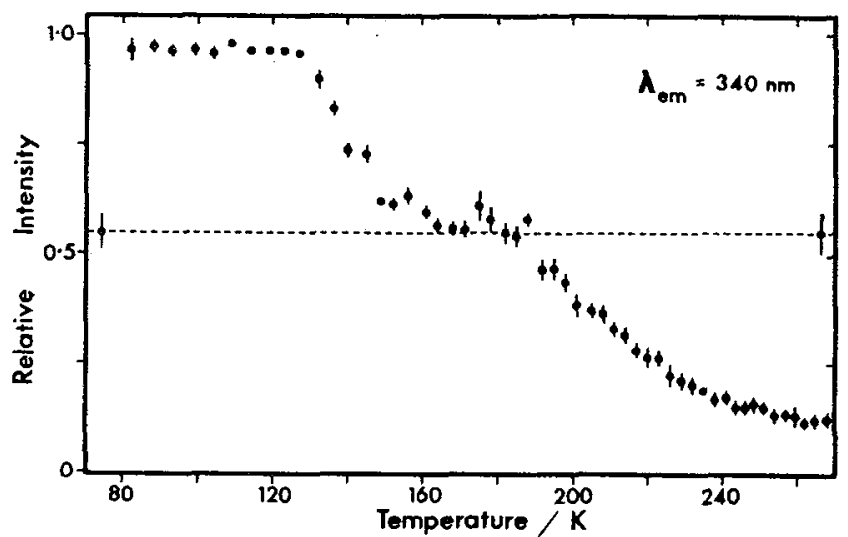

Figure 1. Temperature Dependence of tne loe Luminescence.

Figure $I$ shows che tedicuive dependence of the 340 nm emission after 7 hours of irradiation with 220 nm light using a $20 \mathrm{~nm}$ bandpass. The emission intensities varied from sample to sample and were obtained from 7 plots that had been normalised to give equal areas uajer tine emission spectra.

Upon slowly warming the sample from $82 \mathrm{~K}$, the emission intensity did not change until about $125 \mathrm{~K}$, after which it fell to a new plateau level extending from about $160 \mathrm{~K}$ to $190 \mathrm{~K}$ and which corresponded to the luminescence intensity of previously unirsadiated ice. On warming the ice above $190 \mathrm{~K}$ the intensity 
gradually decreased further, but at $268 \mathrm{~K}$, significant intensity was still present but was ca. one quarter of the intensity observed from previously unirradiated ice.

It was found that the intensity of the accumulated emission also fell when a previously irradiated ice sample at 82 K was slowly warmed to $160 \mathrm{~K}$ and immediately recooled to $82 \mathrm{~K}$.

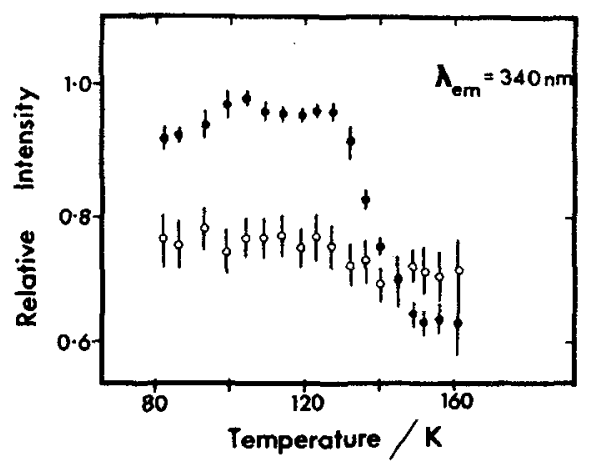

Figure 2. Showing loss of accumulated intensity on heating from $82 \mathrm{~K}(\bullet)$ followed by re-cooling to $82 \mathrm{~K}$ and then re-heating (o).

Figure 2 shows the effect of temperature on the emission intensity when the ice was slowly warmed: (e) after 5 h of continuous irradiation with 220 nm light, and (o) after subsequently recooling the ice sample from $160 \mathrm{~K}$ to $82 \mathrm{~K}$. The emission intensity of the annealed sample which had been returned to $82 \mathrm{~K}$, was greatly reduced and was almost at the same intensity as both the narrow high-temperature $(160 \mathrm{~K}-190 \mathrm{~K})$ plateau shown in Figure 1 and the luminescence of previously unirradiated ice. When the annealed ice sample was rewarmed the emission intensity remained constant over the $82 \mathrm{~K}$ to $160 \mathrm{~K}$ temperature range.

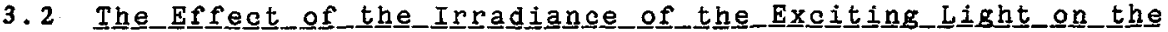

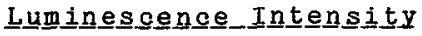

Kinetic studies which examine the effect of changing the irradiance on the emission intensity are analogous to measurements of initial reaction rate as a function of initial reactant concentration. It has previously been shown [2] that the emission intensity, I, and the irradiance, L, of the exciting light should give a linear plot of In $I_{0}$ against ln L with a slope, m, which is equal to the reaction order of the rate determining step of the emission processes, i.e.

$$
m=d\left(\ln I_{0}\right) / d(\ln L)
$$

This relationship was studied over a sevenfold variation in $L$ by inserting filters in the excitation pathway to reduce the intensity of the light incident on the ice. At an emission wavelength of $340 \mathrm{~nm}$, the mean of the slopes, m, for three separate ice samples. was $0.97 \pm 0.01$. This résult indicates that the rate-determining step is first order. 
Attempts to determine the time-dependence of the Iuminescence by shuttering the excitation source showed that it decayed with a half-life which was shorter than 0.1 s and which could not be measured with the present equipment.

\subsection{The}

The species which are likely to be produced in significant concentrations by the photolysis of ice with $220 \mathrm{~nm}$ light are: $\mathrm{H}_{2} \mathrm{O}, \mathrm{H}_{3} \mathrm{O}, \mathrm{H}, \mathrm{OH}, \mathrm{HO}_{2}, \mathrm{H}_{2} \mathrm{O}_{2}$ and $\mathrm{H}_{2}$. The observed increase of the $340 \mathrm{~nm}$ emission intensity with irradiation time suggests the accumulation of a photolytically-produced species which on subsequent irradiation either directly luminesces or is a precursor to the emitting species. It was also observed that upon warming the ice to $160 \mathrm{~K}$ and remcooling it, the emission intensity was reduced to a level almost corresponding to the luminescence intensity of previously unirradiated ice. This suggests that the accumulating species is stable in the ice lattice at temperatures up to ca. $125 \mathrm{~K}$.

The species $\mathrm{H}_{2} \mathrm{O}, \mathrm{H}_{3} \mathrm{O}, \mathrm{H}_{2} \mathrm{O}$ and $\mathrm{H}_{2}$, can be readily eliminated as sources of the $340 \mathrm{~nm}^{2}$ emission. The $\mathrm{H}_{2} \mathrm{O}$ molecule has short-lived excited states and even the occasionaliy postulated [3,4] longer-lived triplet state of $\mathrm{H}_{2} \mathrm{O}$ is said to have a half-life of the order of microseconds. Consequently, excited water molecules cannot accumulate in the way observed. Similarly, $\mathrm{H}_{3} \mathrm{O}$ cannot accumulate, as calculations have shown [5].that it is an unstable intermediate. $\mathrm{H}_{2} \mathrm{O}_{2}$ and $\mathrm{H}_{2}$ are considered to be stable [6-9] species in an ice lattice at temperatures up to 273 K. Consequently, their concentrations would not be expected to show the marked temperature dependence exhibited by the 340 nm emission.

The $H$ atom and the $O H$ and $H O$ radicals are all known to accumulate in the ice lattice. The $H$ atom and the Ho, radical become mobile and disappear by reaction $[6,7,10]$ at ${ }^{2} 50 \mathrm{~K}$ and $145 \mathrm{~K}$, respectively. These temperatures are well removed from the temperature at which the $340 \mathrm{~nm}$ emission begins to disappear. In contrast, the oH radical anneals out rapidly [6,7,10] between $110 \mathrm{~K}$ and $130 \mathrm{~K}$ and is thus a likely precursor of the $340 \mathrm{~nm}$ emission.

The emission could arise directly from oH ${ }^{*}$ produced by a first order reaction, or from a product. Y, of the reaction:

$$
\mathrm{OH}+\mathrm{X}--\rightarrow \mathrm{Y}
$$

where $x$ represents a species which is mobile in the ice lattice at $82 \mathrm{~K}$. Y could then be excited by further incident photons and emit luminescence. The latter excitation step could thus produce the observed first-order dependence of luminescence intensity on irradiance.

$\mathrm{H}$ and $\mathrm{H}$ are possible candidates for the mobile species, $X$, in which case $\mathrm{Y}$ is $\mathrm{H}_{2} \mathrm{O}$ or $\mathrm{H}$. $\mathrm{H}_{2} \mathrm{O}$ can be eliminated from candidacy as it is already present in dominant concentration in the ice itself. Atomic hydrogen produced in an excited state would indeed be mobile in the ice lattice at $82 \mathrm{~K}$ and if free from significant interactions, would produce the characteristic Balmer emission lines in the visible region of the spectrum. However, there is no Balmer emission line in the vicinity of $340 \mathrm{~nm},\left[\left(\mathrm{H}_{2} \mathrm{O}\right)_{\mathrm{H}^{*}} \mathrm{H}^{*}\right.$, or $\left(\mathrm{H}_{3} \mathrm{O}\right)^{*}$, have been proposed [5] as emitters at ca. $405 \mathrm{~nm}$ in U.V. 
photolysed aqueous solutions at $77 \mathrm{~K}$. However,this wavelength is well removed from 340 nm and this species is thus unlikely to be responsible for the emission at that wavelength. Furthermore, atomic hydrogen exhibits [11] a structureless U.V. absorption spectrum, which shows only a steep increase towards 200 nm. It would therefore be unlikely to produce the structured excitation spectrum associated with the $340 \mathrm{~nm}$ luminescence.

However, the absorption spectrum of ice which has been flashphotolysed with U.V. light, consists [12] of a broad absorption band with a peak at $245 \mathrm{~nm}$. Absorption peaks at $230 \mathrm{~nm}$ and $280 \mathrm{~nm}$ observed [8] in pulse-irradiated ice, have also been assigned [12] to the $0 H$ radical. If all these assignments are correct, the position of the $O H$ absorption evidently depends on the energy of the radiation used and/or on the time after excitation at which the spectrum is measured. The 220 nm excitation spectrum peak observed in the present work is therefore not inconsistent with $0 \mathrm{H}$ absorption.

Transitions between the $A^{2} \Sigma^{+}$and $X^{2} \pi$ electronic states of the $O H$ radical are ubiquitous in excited gas phase systems which contain even small amounts of water vapour. It is therefore not surprising that this transition has been suggested [13-16] as a source of the U.V. emission observed from various condensed-phase aqueous systems. This transition of $O H$ has also been used to explain the broad absorption $[8,9,17]$ and emission [18] bands observed in irradiated $\mathrm{H}_{2} \mathrm{O}$ ice. It would not be surprising therefore, if the same transition, red-shifted from its gas phase maximum at 306.4 nm [19], is responsible for the 340 nm band emitted by U.V. photolyzed ice.

Ultraviolet light at $220 \mathrm{~nm}$ is not energetic enough to dissociate a water molecule into $H$ and excited state oH. The production of excited $O H$ therefore probably proceeds via the initial dissociation of $\mathrm{H}_{2} \mathrm{O}$ into ground state $\mathrm{H}$ and $\mathrm{OH}$, the latter being stably [6,7,10] trapped in the ice matrix where it is excited by the absorption of another U.V. photon.

The + intengity distribution of vibrational bands within the $A_{\Sigma}^{+}--\rightarrow X_{\pi}^{2}$ electronic transition of gaseous oH is determined by the magnitudes of the Franck-Condon factors for each $v^{\prime}$ ' $\left\langle---v^{\prime}\right.$ transition, where $v^{\prime \prime}$ and $v^{\prime}$ refer to the ground state and the excited electronic state, respectively, of gaseous oH. All that is required to account for the implied red-shift is a perturbation of the Franck-Condon factors so that the maximum overlap occurs one

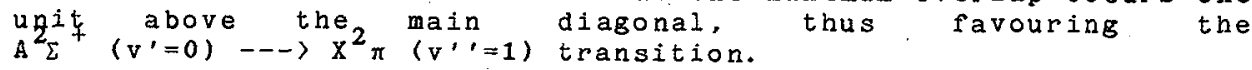

The red-shift of the emission maximum implies, on this basis, a corresponding blue-shift of the absorption maximum from $306.4 \mathrm{~nm}$. It is therefore not unreasonable that the excitation wavelength of the 340 nm gas phase emission of $O H$ should be shifted to $220 \mathrm{~nm}$ which may correspond to the peak of the blue-shifted absorption by $\mathrm{OH}$ in the ice.

Spectral shifts of the emission and absorption maxima of oH have been reported in ice excited by other modes. A broad absorption band which extends from 200 to $340 \mathrm{~nm}$ in the spectrum of ice subjected to gamma-ray $[8,9]$ and pulseq electrons [17], is widely considered to be the $x^{2} \pi\left(v^{\prime}=0\right)-\cdots A^{2} \Sigma^{+}\left(v^{\prime}=1\right)$ transition of oH the peak maximum being shifted from $306.4 \mathrm{~nm}$ to $280 \mathrm{~nm}$. The emission band which peaks at ca. $385 \mathrm{~nm}$ in pulse jrradiated, crystaline ice at $88 \mathrm{~K}$ has been assigned [20] to the $\mathrm{A}_{\Sigma}{ }^{2}\left(\mathrm{v}^{\prime}=0\right)$ $\rightarrow x_{\pi}^{2}\left(v^{\prime},=2\right)$ transition of $0 H$. It thus seems likely that both 
the absorption and emission assignments involve perturbation of the Franck-Condon factors to favour transitions which are off the main diagonal.

\section{ACKHOULBDGBHENTS}

The authors gratefully acknowledge a number of helpful discussions with Mr. D.F. Sangster of the CSIRO Division of Chemical Physics. R.A.J.L. gratefully acknowledges the tenure of a Postgraduate Research Studentship from the Australian Institute of Nuclear Science and Engineering and the award of a University of Western Australia Research Studentship during the latter stages of this work.

\section{REFEREHCES}

1. T.I. Quickenden, R.A.J. Litjens, C.G. Freeman, and

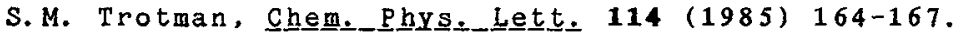

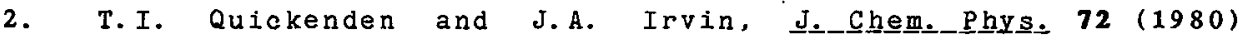
4416-4428.

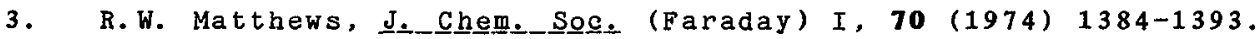

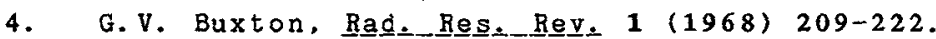

5. T.L. Mathers, R.V. Nauman, and S.P. MoGlynn, Chem._Phys._Lett. $126(1986) \quad 408-412$.

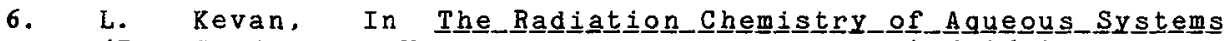
(Ed. G. Stein, Weizmann Seience, Jerusalem) (1968).

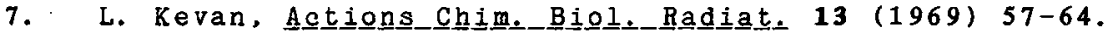

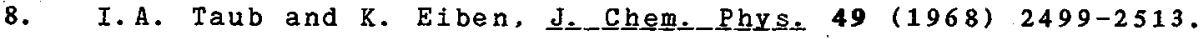

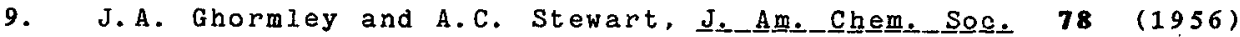
2934-2939.

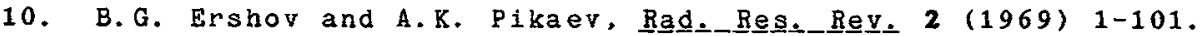

11. J.W. Boyle, J.A. Ghormley, C.J. Hochanadel, and J.F. Riley, J.-므모._대트. $73(1969) 2886-2890$.

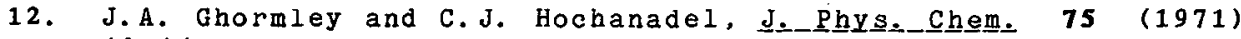
40-44.

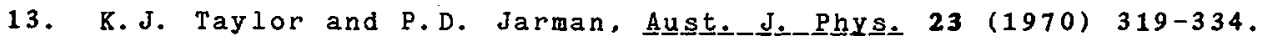

14. H.J. Maria and S.P. McGlynn, J_-

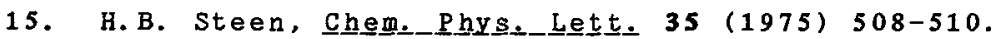

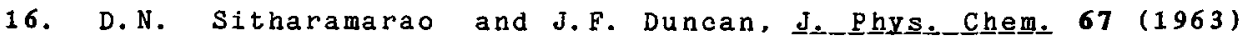
2126-2132.

17. Z. Wu, H.A. Gillis, N.V. Klassen and T.G. Teather,

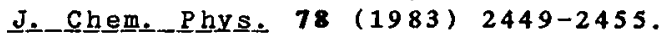

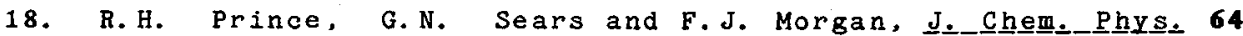
(1976) 3978-3984. 


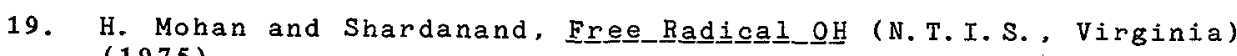
(1975).

20. S.M. Trotman, T.I. Quickenden and C.G. Freeman, J._Chem._Phys. $85(1986) \quad 2555-2568$.

\section{COMMENTS}

M. A. White

Have you tried any experiments concerning thermoluminesce of ice?

Answer :

Preliminary attempts have been made to observe thermoluminesce from crystalline ice, primarily to ascertain whether any component of the emission at $340 \mathrm{~nm}$ was due to this source. No thermoluminesce with an emission wavelength of 340 nm was detected with the present apparatus. 